\title{
In situ cyanoacrylate glue "thrombus" formation during cardiac de-airing
}

\author{
Bari Murtuza, PhD, FRCS, ${ }^{a}$ Amina Khalil, MRCS, ${ }^{a}$ Rudiger Stenz, MD, ${ }^{\text {b }}$ and Mario Petrou, PhD, FRCS(CTh), \\ London, United Kingdom
}

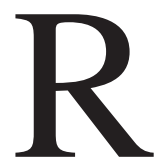

ecently reported acute complications associated with biological tissue sealants in cardiac surgery have prompted the use of more rapidly polymerizing cyanoacrylate compounds. We describe, however, that de-airing after aortic valve replacement (AVR) represents a critical window during which these newer agents can lead to potentially life-threatening glue "thrombus" formation.

\section{Clinical Summary}

Elective AVR was performed in an 86-year-old woman with critical aortic stenosis (valve area $0.67 \mathrm{~cm}^{2}$ ). After median sternotomy, right atrial-ascending aorta cardiopulmonary bypass (CPB) was instituted with myocardial protection using systemic hypothermia $\left(32^{\circ} \mathrm{C}\right)$ and antegrade and retrograde cold-blood cardioplegia. A left ventricular vent was placed through the right superior pulmonary vein. A lazy-"S" aortotomy revealed a calcified tricuspid aortic valve. After valvectomy and debridement, a 21-mm Perimount valve (Carpentier-Edwards, Irvine, Calif) was implanted using a semicontinuous 2-0 Prolene suture (Ethicon Inc, Somerville, NJ). Coronary clearance was confirmed, and the aortotomy was closed with a single-layer 4-0 Prolene suture buttressed with bovine pericardial strips. Omnex cyanoacrylate glue (Johnson \& Johnson, Berkshire, UK) was applied prophylactically to the suture line, and a rigorous de-airing drill commenced. This comprised 3 cycles of alternate filling of the left heart and suctioning through the left ventricle and aortic root vents with manual ventilation. De-airing was monitored by transesophageal echocardiography (TEE). The aortic crossclamp was removed, and after 10 minutes of reperfusion (maintaining root vent suction), separation from CPB was achieved with sinus rhythm and good cardiac action. Before protamine administration, TEE confirmed a normal opening of the prosthetic valve and no associated leak, but showed a large mass within the aortic root associated with the suture line (Figure 1). CPB was reinstituted, and the suture line was taken down to reveal a solidified glue "thrombus" within the aorta (Figure 2). This was extracted, and the aortotomy closure was revised using bovine pericardium without glue. A repeat TEE confirmed a good

From the Departments of Cardiothoracic Surgery ${ }^{\mathrm{a}}$ and Anesthesia, ${ }^{\mathrm{b}}$ Royal Brompton Hospital, London, United Kingdom.

Received for publication Oct 2, 2006; accepted for publication Oct 24, 2006.

Address for reprints: Bari Murtuza, PhD, FRCS, Department of Cardiothoracic Surgery, Royal Brompton Hospital, Sidney Street, London, SW3 6N9, UK (E-mail: b.murtuza@rbh.nthames.nhs.uk).

J Thorac Cardiovasc Surg 2007;133:805-6

$0022-5223 / \$ 32.00$

Copyright (C) 2007 by The American Association for Thoracic Surgery

doi:10.1016/j.jtcvs.2006.10.051 result. The patient made a good postoperative recovery with no features to suggest embolization of glue fragments.

\section{Discussion}

Bleeding from suture lines and suture holes in the fragile aorta after AVR is a challenging problem that may lead to hemodynamic instability and the need for surgical reexploration with increased morbidity and mortality. Surgical sealants are commonly used in cardiac surgery and have been suggested to reduce blood loss and enhance tissue integrity. An albumin-glutaraldehyde sealant (BioGlue, Cryolife Inc, Kennesaw, Ga) is widely used in this context. ${ }^{1}$ This type of sealant begins to solidify within 30 seconds with peak strength within 2 to 3 minutes. Its use around aortic suture lines has led to seepage into the aortic root with impingement and malfunction of implanted prosthetic aortic valves. Other thromboembolic phenomena include acute peripheral arterial occlusion. ${ }^{2}$ Cyanoacrylate glues exhibit ultrarapid polymerization, with a mean time to hemostasis of 9.1 seconds on contact with water. Cyanoacrylate glues were used during the Vietnam War as wound sealants. They have been used in cardiac surgery to repair myocardial lacerations and more recently for aortic suture lines. ${ }^{3,4}$

Earlier cyanoacrylates were associated with marked tissue inflammation. ${ }^{4}$ Although newer agents are safe in this respect, the case presented here demonstrates that in situ thrombus formation can still occur after ingress of glue through even 4-0 suture holes, despite the rapid onset of action. This seepage of glue is likely to be accelerated in the context of negative pressure within the aortic root during de-airing; thus, glue polymerization can occur ectopically rather than on the outer surface of the aorta. The de-airing sequence before crossclamp removal spans 3 to 5 minutes, so it is not likely that further glue would enter the aortic root after this, despite continued root vent suction. There would, however, be the

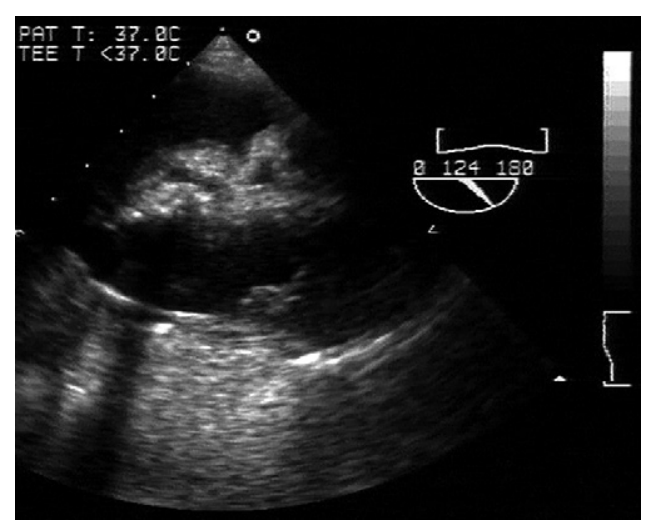

Figure 1. Intraoperative TEE demonstrating the presence of a large mass of solidified glue within the aortic root. TEE, transesophageal echocardiography. 


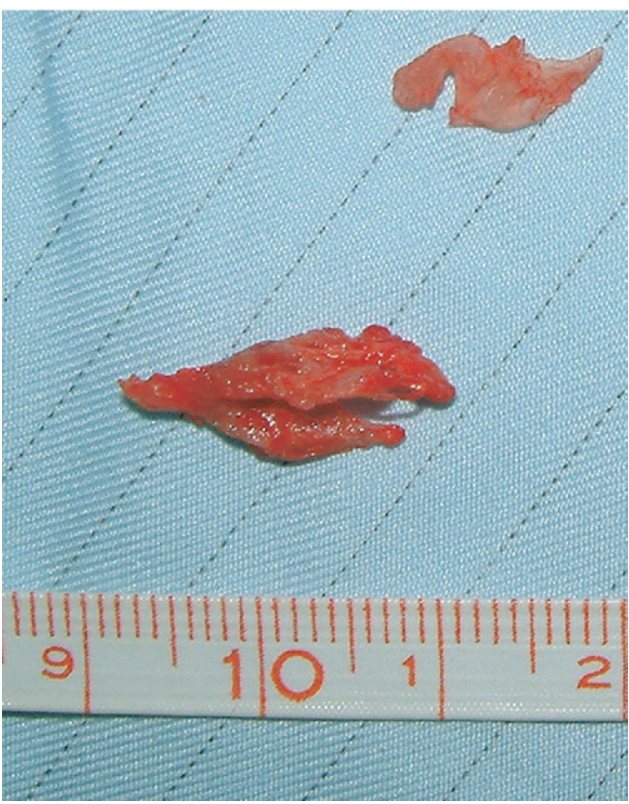

Figure 2. Fragments of glue extricated from aortic root (ruler scale in centimeters). persistent threat of embolization and potential frustration of the prosthetic valve with a beating heart after clamp removal.

De-airing of the heart after AVR using a standard, rigorous technique with aortic root and left ventricular vents creates transient conditions during which negative pressure and low, turbulent flows exist. These conditions may favor the aggregation of glue particles once inside the aorta in a similar fashion to conditions favoring thrombus formation as stated in Virchow's triad. ${ }^{5}$ We propose that even rapidly polymerizing cyanoacrylate glues should be used with caution at aortic suture lines and, in particular, that the timing of application with respect to de-airing using aortic root vents is critical.

\section{References}

1. Karimi M, Kerber RE, Everett JE. Mechanical aortic valve malfunction an intraoperative BioGlue complication. J Thorac Cardiovasc Surg. 2005; 129:1442-3.

2. Guerrero MA, Cox M, Lumsden AB, Reardon M, Howell J. Embolus of surgical adhesive to the extremities causing acute ischemia: report of two cases. J Vasc Surg. 2004;40:571-3.

3. Robicsek F, Rielly JP, Marroum MC. The use of cyanoacrylate adhesive (Krazy Glue) in cardiac surgery. J Card Surg. 1994;9:353-6.

4. Braunwald NS. A clinical evaluation of methyl-2-cyanoacrylate monomer as a hemostatic agent on the aorta. Ann Surg. 1966;164:967-72.

5. Lowe GD. Virchow's triad revisited: abnormal flow. Pathophysiol Haemost Thromb. 2003;33:455-7.

\title{
Mechanical valve obstruction caused by an occlusion device
}

\author{
Ofer Merin, MD, Dani Bitran, MD, Daniel Fink, MD, Esther Asher, MA, and Shuli Silberman, MD, Jerusalem, Israel
}

$\mathrm{M}$ echanical occlusion devices are used mainly for the closure of septal defects or patent ductus. There have been some reports of their use for the closure of paravalvular leaks after valve replacement. The potential for leaflet obstruction of a mechanical mitral prosthesis has so far been unrecognized. This is the first report of this potential complication.

\section{Clinical Summary}

A 74-year-old woman underwent coronary bypass and aortic valve replacement with a mechanical device 13 years ago. Two years

\footnotetext{
From the Department of Cardiothoracic Surgery, Shaare Zedek Medical Center, Jerusalem, Israel.

Received for publication Sept 27, 2006; accepted for publication Oct 30, 2006.

Address for reprints: Shuli Silberman, MD, Department of Cardiothoracic Surgery, Shaare Zedek Medical Center, PO Box 3235, Jerusalem, Israel 91031 (E-mail: ssilberman@ szmc.org.il).

J Thorac Cardiovasc Surg 2007;133:806-7

$0022-5223 / \$ 32.00$

Copyright $\odot 2007$ by The American Association for Thoracic Surgery doi:10.1016/j.jtcvs.2006.10.048
}

before the current admission, she underwent a second operation to replace her mitral valve because of heart failure secondary to severe mitral incompetence. Her valve was replaced with a St Jude 25-mm valve (St Jude Medical, St Paul, Minn). Shortly thereafter, shortness of breath developed in the patient, and a severe paravalvular leak was seen on the mitral prosthesis. She then underwent attempted closure of the paravalvular leak with percutaneous insertion of an Amplatzer occlusion device (AGA Medical Corporation, Golden Valley, Minn). Her condition continued to deteriorate, hemolytic anemia developed, and severe mitral regurgitation persisted (seen on echocardiography as an eccentric jet). Fluoroscopy (Figure 1) showed that 1 of the valve leaflets, adjacent to the device, was immobile. She was then referred to our department for repeat mitral valve replacement. The occlusion device was found to impinge on the posterior leaflet, restricting it in a closed position (Figure 2). The mitral valve was replaced with a bioprosthesis. The operation and immediate postoperative course were uneventful; however, on the day after surgery massive bleeding developed from the mediastinal drains. Emergency exploration was undertaken in the intensive care unit, which revealed bleeding from the area of the inferoposterior left ventricular wall, suggestive of atrioventricular rupture. The patient could not be resuscitated, and she died. Reexamination 